\title{
A Conversation Between Uwe Haberkorn and Johannes Czernin
}

\author{
Uwe Haberkorn $^{1}$ and Johannes Czernin ${ }^{2}$ \\ ${ }^{1}$ University Hospital Heidelberg and DKFZ, Heidelberg, Germany; and ${ }^{2}$ David Geffen School of Medicine at UCLA, Los Angeles, \\ California
}

$\mathbf{J}$ ohannes Czernin, editor in chief of The Journal of Nuclear Medicine, initiated in 2019 a series of recorded discussions with leaders in nuclear medicine and molecular imaging. For this issue, he talked with Uwe Haberkorn, MD, PhD, professor of nuclear medicine at the University Hospital/University of Heidelberg and head of the Clinical Cooperation Unit in Nuclear Medicine at the German Cancer Research Center (Deutsche Krebsforschungszentrum [DKFZ]; both in Heidelberg, Germany). After moving from ultrasound and CT to nuclear medicine, he soon established a molecular biology laboratory and concentrated first in tumor metabolism related to the expression of the relevant genes, then moved to apoptosis imaging and the use of benzamides for diagnosis and therapy of melanomas, both together with his colleague Michael Eisenhut. Fascinated by the use of viral vectors for the transfer of suicide genes into tumors, he worked on the construction of adenoassociated vectors bearing tissue-specific promoters and then on the development of virla vectors transferring antiangiogenetic genes in tumors. Finally, he concentrated on the use of high-throughput methods such as phage and ribosome display for the identification of peptides binding to target proteins overexpressed in tumors. $\mathrm{He}$ has been awarded the Mallinckrodt Prize of the German Society for Nuclear Medicine (1996), the First Prize for Contrast Research from the German Röntgen Society (1998), and the Erwin Schrödinger Prize of the Helmholtz Association of German Research Institutes (2018).

Dr. Czernin: Your educational path was somewhat unusualyou started out studying philosophy for $2 y$.

Dr. Haberkorn: I didn't study philosophy alone. I also studied German literature. My initial intention was to study classic German philosophers, but I ended up studying contemporary American philosophers like Hilary Putnam, Willard van Orman Quine, and Wilfrid Sellars, and, up to the present day, people like Daniel Dennett and Thomas Nagel. My first intention was to become a philosopher.

Dr. Czernin: And did you graduate with a degree in philosophy?

Dr. Haberkorn: I had a midterm examination in German literature about the History of Agathon from Christoph Martin Wieland after $1 \mathrm{y}$. This was quite fast-half the time one usually needs. I also had a midterm essay ready to submit for philosophy about Gottlob Frege's theory of meaning. It was then that I realized that medicine might be a better job for bread and butter.

Dr. Czernin: It's kind of a survival choice.

Dr. Haberkorn: Maybe, but I realized that when you engage in medical research you may be as creative as a philosopher. Before I

COPYRIGHT @ 2019 by the Society of Nuclear Medicine and Molecular Imaging. studied philosophy, I worked in civil service at an emergency unit of the Red Cross. This gave me more than $1 \mathrm{y}$ of patient contact and perhaps was an additional motivation to change to medicine.

Dr. Czernin: So then you actually studied medicine in Marburg?

Dr. Haberkorn: I did preclinical studies in Marburg, then did $1 \mathrm{y}$ in Würzburg, and thereafter went to Heidelberg. Interestingly, the most boring course during my medical studies was

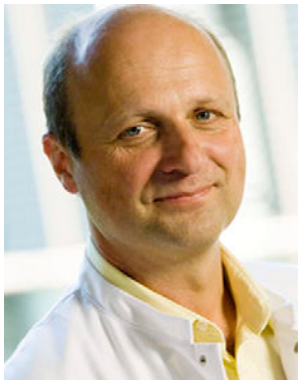

Uwe Haberkorn, MD, PhD radiology and nuclear medicine. At that time my dream was to become a neurologist. I was interested in neurologic disorders, maybe because of my propensity for catastrophes. So this left a choice of neurology (where you could not do much for patients) or cancer (where you could not do much, either). Then, during my studies, someone suggested a doctoral thesis topic about liver ultrasound tissue characterization at the DKFZ. This was more theoretic work, with excised livers and a computerized ultrasound system, but I wanted to try to do real work by doing experiments in fatty liver, cirrhosis, and liver metastasis. The thesis was about correlations between ultrasound tissue parameters and biochemical features of liver tissue like lipid content, connective tissue content, and things like that. This was kind of a radiomics approach, except $30 \mathrm{y}$ ago. It didn't make it into clinical application. Therefore, I am a bit pessimistic about current radiomics activities (greetings from hell).

During my medical studies I continued to attend philosophical seminars. In Würzburg, a professor of philosophy whose research focused on Franz Brentano offered me the opportunity to write a philosophical doctoral thesis about intentionality in Franz Brentano's work, but then I moved to Heidelberg where I did my thesis in ultrasound.

Dr. Czernin: And then you moved over to the DKFZ in Heidelberg?

Dr. Haberkorn: Exactly. It was my doctoral thesis supervisor who offered me a job. That's when my dream of becoming a neurologist died, and I landed first in radiology with ultrasound and CT. After 1 y I realized that these purely morphologic methods were not really what I was interested in. I was allowed by my boss, Gerhard van Kaick to start working with PET. In those days Germany had only 3 PET systems. That was a really nice time. I soon realized that I was more interested in the theoretic side of life. So I slowly created a molecular biology laboratory, where van Kaick gave me all the freedom to realize my ideas. He is really a wonderful person. I learned both by doing and by having the advice of Heidelberg experts in molecular biology. But basically I learned 
by doing. In fact, most of the techniques that we use in my lab now I learned and applied myself.

Dr. Czernin: So you are an autodidact in molecular biology?

Dr. Haberkorn: Yes. But I also got advice from very competent technicians, some of whom are still working with me.

Dr. Czernin: There's a pretty substantial disconnect between the preclinical and the clinical sciences. Often the basic scientists don't quite understand what the clinical needs are, whereas the clinical scientists have no clue what the basic scientists can do. How did you start to bridge this gap?

Dr. Haberkorn: That was difficult initially, although van Kaick and Harald zur Hausen allowed me to install a clinical cooperation unit in nuclear medicine at the DKFZ. Therefore, I am still connected to the DKFZ. However, when I moved from the DKFZ to the university hospital, this was quite a big change for the first $2 \mathrm{y}$, because I saw a lot of cancer and thyroid patients in routine clinical care. At that time, I was the only physician in the department who was board certified in nuclear medicine. I was, therefore, always ready to provide clinical service. On the positive side, I also realized that doing science must bring value for taxpayers, which means value for patients. After a long period of theoretic work, including tumor metabolism, apoptosis, and gene therapy of different kinds, it became clear that much of the theoretic work I had done before lacked translational potential. This was the key reason to change the program toward drug development. We have now been working for $14 \mathrm{y}$ on various methods
Dr. Czernin: You started out talking about an antibody construct yet you then moved over to peptides. Do you want to comment on antibodies vs. peptides?

Dr. Haberkorn: Because we cannot do everything at a high level, our policy in Heidelberg is to concentrate on peptides or small molecules. Both antibodies and peptides/small molecules have advantages and disadvantages. It is easy to identify antibodies using high-throughput methods, but it is much harder to identify peptide ligands with these methods. But if you have peptides/small molecules identified, then the pharmacokinetics are favorable compared with antibodies, at least for imaging, and I think also for therapy.

Dr. Czernin: The reason why I'm asking the question is because we tend to sometimes undervalue antibodies and are largely focused on peptides. The interesting comment that you made here is that your choice is not based on fundamental advantages or disadvantages but rather on the competence and expertise of your lab.

Dr. Haberkorn: Correct. If you have a wonderful antibody, why not use it? I'm a pragmatist: if you have a good ligand, then you should use this ligand irrespective of what format it has. In the end, it is for the patient and not for your personal vanity.

Dr. Czernin: Let me get back for a moment to the biologic underpinning for selecting FAP as a target. What is your hypothesis on mechanism of action in terms of therapeutic effect as you are targeting tumor stroma and not primarily tumor cells?

"I think we should take a look outside our field and add some features to science that take us into more risky projects, even if this means neglecting existing dogmas. Maybe the most innovative endeavors have, let's say, a $99 \%$ chance to fail. So what? I think innovative scientists should love failures. Or at least accept them."

to identify cancer cell surface targets and ligands, mainly by high-throughput biotechnology methods. We continue with these efforts today.

Dr. Czernin: Our readers are, of course, familiar with theranostics targeting somatostatin receptors, prostate-specific membrane antigen (PSMA), or $C-X-C$ chemokine receptor 4 . You have focused lately on different targets, and you have published quite extensively on some in JNM (1-7). One of your key novel targets is the fibroblast activation protein (FAP), for which you came up with high-affinity ligands. How did you come up with this target, which is especially interesting because it is not a cancer cell but a tumor stromal target?

Dr. Haberkorn: This is a long story-we conducted initial experiments in 2009, when we started with an antibody-based approach that unfortunately failed. In 2010 we made a first attempt using a commercially available peptide library, the $\mathrm{PhD} 12$ library from NEN Biolabs. But this was also not successful. We stopped all these activities in 2011 and started them again in 2014, when we had a project funded by the German Ministry of Research. At that time, we used our own peptide libraries based on scaffold structures like the sunflower trypsin inhibitor (SFTI) and Min-23 for phage and ribosome display but failed again, even after building a FAPspecific library bearing a G-P motif. I realized that maybe these high-throughput methods may work in some cases but not for all targets. Then I realized that specific FAP inhibitors had been described by Jansen et al. (8-10), and our chemists modified these molecules and immediately had success. So you need a little luck.
Dr. Haberkorn: First, I am quite convinced that future studies will show that FAPI (FAP inhibitor) may become a competitor for FDG in some cancers. Concerning therapy, we are attacking the stroma. This is something biologically completely different from the way radionuclide-based cancer therapies have worked. We will treat final-stage patients under compassionate use in the very near future. The idea is to disrupt the communication between the stroma and tumor cells at several levels: by preventing secretion of tumor-stimulating cytokines or chemokines, by inhibiting angiogenesis, and by increasing the accessibility of tumor cells for drugs and the immune system. So as a physician I really hope that these patients who no longer have options will profit from this treatment. I am quite curious to see what happens in these early compassionate use treatments.

Dr. Czernin: For further development, should there be a way to study this theranostic pair prospectively that is different from the approaches used for PSMA or somatostatin receptor-targeted treatments, which saw pivotal trials lagging behind discovery for as much as a decade?

Dr. Haberkorn: Yeah. Of course, what we can do in Heidelberg are retrospective analyses after compassionate use. This may be seen as proof of concept. Prospective studies can be done much faster in the United States or Australia. Regulations in Germany are quite difficult, and it takes a long time to go through them.

Dr. Czernin: FAP is an unusual example, because it is (as you showed in a recent paper [2]), so highly expressed in many cancers. Did you start out with a specific indication in mind, and 
would you now promote a pan-cancer evaluation and development concept? Would you prefer an indication-by-indication validation approach based on expression data?

Dr. Haberkorn: I think it was clear from the literature that this could be a pan-cancer tracer. We see high expression in breast tumors, pancreatic cancers, some sarcomas, colon cancer, lung cancer, and head and neck tumors. Initially I expected 3 to 5 tumor entities in which this tracer could work. I did not expect that it would work in so many cancers. At present, there appears to be a huge field of possible indications, not only in oncology but also in benign diseases with tissue remodeling, perhaps in cardiac disease (such as infarction) as one of the most important fields. This is a task that can be addressed not by a single institution but by the scientific community. So I am curious what happens in the near future.

Dr. Czernin: And when you think about therapeutic trials, would you go by individual cancers or a basket trial in which you use imaging as the key predictive and qualifying biomarker for participation?

Dr. Haberkorn: I would prefer basket trials, at least in the first stages, to determine variations in biology, effects, side effects, and maximum tolerated activity. You need to get an idea about tumor responses and whether they are predictable from imaging. Also we have to determine the maximum activity that can be given, and we have to see if in these basket trials some tumor entities respond better than others. Different tumors may react differently because the interaction between stroma and tumor and even the individual composition of the stroma may very well differ among tumor types. But at this stage this is speculation.

Dr. Czernin: Have you developed good animal models in the meantime?

Dr. Haberkorn: For therapy not yet, but we are working on this. I think that we have to move from human tumors in nude mice to murine tumors in immunocompetent mice. This is a more realistic model for the human situation, because it is closer to the complex tumor-stroma interaction in humans, which includes immunocompetent cells as a very important part of the microenvironment.

Dr. Czernin: I cannot let you go before I ask you what's next in Haberkorn-land.

Dr. Haberkorn: We are currently working on 4 to 5 different targets overexpressed in tumor cells or in the stromal compartment. This is done using our high-throughput systems (i.e., phage and ribosome display with our peptide libraries). Therefore, these are high-risk projects, and we really need a lot of luck to succeed. Basically these are interdisciplinary projects in which my biotechnology group is working together with the chemists. The biotech group identifies peptides with high affinity to the target, and the chemists modify them to create radiopharmaceuticals. After synthesis by the chemists, these molecules are then evaluated in vitro and in vivo by the biotech lab. So I am responsible for the biology/ biotech part.

Dr. Czernin: Your response suggests that you believe that there are quite a few other promising targets out there that can be addressed for theranostics.

Dr. Haberkorn: Too many for me.

Dr. Czernin: Will there be theranostics clinics as part of nuclear medicine clinics?

Dr. Haberkorn: You ask whether theranostics will be part of nuclear medicine or outside of nuclear medicine departments? That sounds like a political question.

Dr. Czernin: No, in this case it's not so much. In my view it should be done in nuclear medicine clinics. But my question was related to patient volumes. Will theranostic clinics have enough patient volume? This should be the case if you include prostate cancer, neuroendocrine tumors, and thyroid cancer, of course. Let's assume FAPI is going somewhere and other targets are addressed successfully: These clinics could become something like traditional oncology chemotherapy outpatient clinics.

Dr. Haberkorn: It was never my strategy to do this work for tumor patients in isolation. You need a close collaboration with oncologists, urologists, endocrinologists, etc. I also see the future not in monotherapy for every theranostic approach. I see it as a combination and integration of strategies for scientific reasons and to provide the best patient care. In addition, you will never get patients for therapy if you don't work closely together with your colleagues from other disciplines, at least in Germany. In Heidelberg we have 1 big hospital with different departments and varying partners for varying medical tasks. In this setting integration of patient care in the workflow of the departments involved in the disease of a patient is the most important aspect.

Dr. Czernin: Do you have a final message for our readers about what you are doing and in what direction the whole field is moving?

Dr. Haberkorn: Actually I am still influenced by philosophy and am also currently thinking of how science could work. Willard van Orman Quine stated in The Web of Belief (written with Joseph Silbert Ullian) that science, not only medical science, has a strong conservative part (11). We usually want to keep what we have, because it is established and proven by many experiments before and that we agree to changes only when inconsistencies appear. He went on to say that inconsistencies usually appear at the edge of the web, where science meets reality, and not at the center, where logic and mathematics are located. You could change some of these inconsistencies at the edge to obtain a better correspondence to the world. This is quite a negative procedure: to change only as a reaction to inconsistencies. Why are we not a little bit more positive by including fantasy in the game? Fantasy doesn't mean uncontrolled fantasy - that would be fiction. But I think we should take a look outside our field and add some features to science that take us into more risky projects, even if this means neglecting existing dogmas. Maybe the most innovative endeavors have, let's say, a 99\% chance to fail. So what? I think innovative scientists should love failures. Or at least accept them. In other words, we may need to look not at a change in the lack of inconsistencies but at a change in the presence of opportunities. To be clear: my goal is not to disavow the activities that serve clinical implementation. I am talking about innovation in new developments, which is a step before.

Dr. Czernin: In terms of fantasy, would you call it creativity or courage?

Dr. Haberkorn: You can call it creativity, but creativity starts with fantasy-when you begin to admit that things might be otherwise than we have all thought for years. This means that you may put into question the dogmas we have in daily scientific life. For example, when validating a target you may realize that shedding of a membrane-bound protein occurs and that the shedded part appears in the blood and can be used as a tumor marker. In former times, this was a knockout criterion for me. Now I think that I was wrong. Many of the targets that we use in nuclear medicine are shed or have secreted isoforms and are still useful for imaging. It's a matter of quantity. This is what I mean by challenging the dogmas. Of course we shouldn't change the 
whole system, only small parts of it. In that respect Quine was completely right. However, why should we not be a bit more audacious or prepared to take scientific risks by engaging in projects that may fail? Maybe this is a point of view we are missing in current funding policies, which are rather conservative (maybe too conservative). Related to that, if you concentrate only on projects where you know in advance how things will turn out, you can't generate really innovative science. That's my opinion, and I could be wrong.

\section{REFERENCES}

1. Varasteh Z, Mohanta S, Robu S, et al. Molecular imaging of fibroblast activity after myocardial infarction using a ${ }^{68} \mathrm{Ga}$-labelled fibroblast activation protein inhibitor FAPI-04. J Nucl Med. August 12, 2019 [Epub ahead of print].

2. Kratochwil C, Flechsig P, Lindner T, et al. ${ }^{68} \mathrm{Ga}$-FAPI PET/CT: tracer uptake in 28 different kinds of cancer. J Nucl Med. 2019;60:801-805.

3. Loktev A, Lindner T, Burger EM, et al. Development of novel FAP-targeted radiotracers with improved tumor retention. J Nucl Med. March 8, 2019 [Epub ahead of print].
4. Giesel FL, Kratochwil C, Lindner T, et al. ${ }^{68} \mathrm{Ga}$-FAPI PET/CT: biodistribution and preliminary dosimetry estimate of 2 DOTA-containing FAP-targeting agents in patients with various cancers. J Nucl Med. 2019;60:386-392.

5. Roesch S, Lindner T, Sauter M, et al. Comparison of the RGD motif-containing $\alpha_{v} \beta_{6}$ integrin-binding peptides SFLAP3 and SFITGv6 for diagnostic application in HNSCC. $J$ Nucl Med. 2018;59:1679-1685.

6. Loktev A, Lindner T, Mier W, et al. A tumor-imaging method targeting cancerassociated fibroblasts. J Nucl Med. 2018;59:1423-1429.

7. Lindner T, Loktev A, Altmann A, et al. Development of quinoline-based theranostic ligands for the targeting of fibroblast activation protein. $\mathrm{J} \mathrm{Nucl} \mathrm{Med}$. 2018;59:1415-1422.

8. Jansen K, Heirbaut L, Cheng JD, et al. Selective inhibitors of fibroblast activation protein (FAP) with a (4-quinolinoyl)-glycyl-2-cyanopyrrolidine scaffold. ACS Med Chem Lett. 2013;4:491-496.

9. Jansen K, Heirbaut L, Verkerk R, et al. Extended structure-activity relationship and pharmacokinetic investigation of (4-quinolinoyl)glycyl-2-cyanopyrrolidine inhibitors of fibroblast activation protein (FAP). J Med Chem. 2014;57:3053-3074.

10. De Decker A, Vliegen G, Van Rompaey D, et al. Novel small molecule-derived, highly selective substrates for fibroblast activation protein (FAP). ACS Med Chem Lett. 2019;10:1173-1179.

11. Quine WV, Ullian JS. The Web of Belief. New York, NY: McGraw-Hill Book Company; 1978 